\title{
Novel Solid State Cladding of Brass to Steel Plate by Friction Stir Welding*
}

\author{
by Toshikazu MATSUYAMA**, Takuya TSUMURA*** and Kazuhiro NAKATA***
}

\begin{abstract}
To use brass as a tribological material instead of $\mathrm{Pb}$ bronze, the feasibility of forming a lap joint of brass sheet on steel plate was investigated by using Friction Stir Welding, and it was proved that a lap joint with smooth surface and good joint strength was successfully made. Furthermore, the mechanism taking place at the lap joint of brass to steel was discussed by observing the interface.
\end{abstract}

Key Words: $\quad$ Brass, Medium Carbon Steel, FSW, Lap Joint

\section{Introduction}

Lead bronze has been widely used as a tribological material for use in the sliding parts of hydraulic equipment. However, the European Union Regulation, REACH, has restricted the use of materials containing lead as an alloying element, such as lead bronze. Brass is viewed as a replacement for lead bronze because of its good tribological properties. However, cladding brass on steel parts is difficult to accomplish by overlaying or other fusion-welding processes because brass contains zinc, which has a lower boiling point than copper. Therefore, solid-state welding is indispensable for cladding brass on steel.

Friction Stir Welding (FSW), a solid-state welding process, is well known, and its use for the dissimilar metal joining has been reported on the combination of $\mathrm{Al}$ alloy and steel [1,2]; $\mathrm{Mg}$ alloy and steel [3]; Ti alloy and steel [4]; Inconel alloy and steel [5]; Al alloy and $\mathrm{Mg}$ alloy [6]; and aluminum and copper [7-10]. However, the formation of a lap joint of brass and steel via FSW has not been reported yet.

In this study, the feasibility of forming a lap joint between a brass sheet and a steel plate by FSW was investigated, and the microstructures and mechanical properties of the Friction Stir Welded brass and steel lap joint were evaluated.

*Received: 2012.11.29

${ }^{* *}$ Graduate, School of Engineering, Osaka University, Japan

*** Joining and Welding Research Institute, Osaka University, Japan

\section{Experiments}

A $60 \mathrm{Cu}-40 \mathrm{Zn}$ brass sheet with dimensions of $200 \mathrm{~mm} \times 100$ $\mathrm{mm} \times 3 \mathrm{~mm}$ and a plain carbon steel (S25C) plate with dimensions of $200 \mathrm{~mm} \times 100 \mathrm{~mm} \times 5 \mathrm{~mm}$ were used in the present work. The brass sheet was lap-joined to the steel plate by FSW, as shown in Fig. 1 (a), by placing the brass sheet on top of the steel plate.

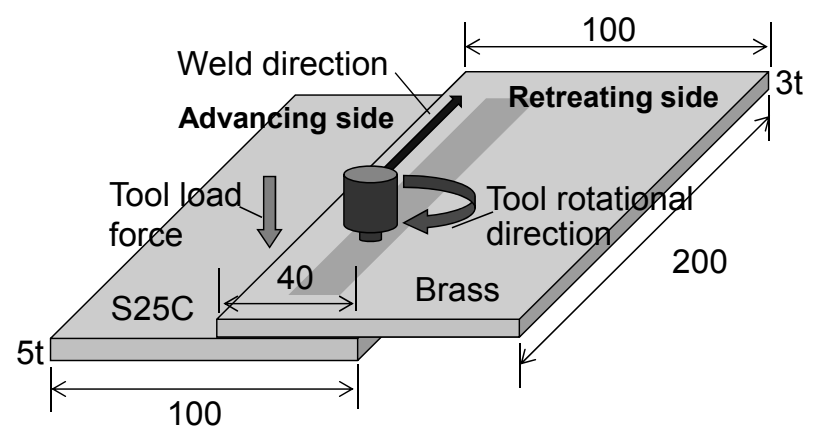

(a) Overall view

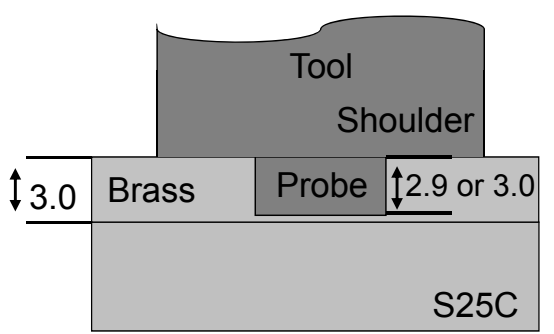

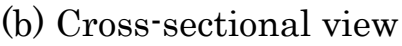

Fig. 1 Schematic diagram of lap joint by FSW: (a) overall view and (b) cross-sectional view. 


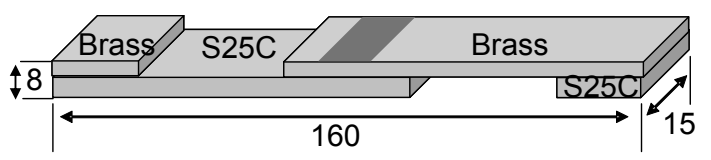

Fig. 2 Schematic view of specimen for tensile shear test.

Two types of FSW tool, made of steel (SKD61) and WC-Co. Each tool had a 15-mm-diameter concave shoulder and a 6-mm-diameter probe. The probe of the SKD61 tool had threads but that of the WC-Co tool did not because of its low cutting performance. The length of each probe was $2.9 \mathrm{~mm}$ or $3.0 \mathrm{~mm}$, which corresponded to the thickness of the brass sheet, as shown in Fig. 1 (b).

FSW was performed under different welding conditions: a tool force of 9.8-19.6 kN, a tool rotation speed of 750-1750 rpm, and a welding speed of $250-2000 \mathrm{~mm} / \mathrm{min}$ using a load-control-type FSW machine. The tool was tilted $3^{\circ}$ forward from the vertical to make a good weld surface.

A tensile shear test was performed to evaluate the fracture strength of the welded joints. A schematic view of the specimen used for the tensile shear test is shown in Fig. 2. The two tensile shear test specimens were cut from each joint perpendicular to the weld bead at the central area, and the tensile shear strength per unit width of the specimen was evaluated.

\section{Results and Discussion}

\subsection{Results using SKD61 tool}

The effect of the rotation speed and welding speed on the friction-stir weldability of a lap joint at tool force $9.8 \mathrm{kN}$ using the SKD61 tool with a $2.9-\mathrm{mm}$-long probe is summarized in Fig. 3. Condition zone A resulted in excess burrs and probe tip damage; condition zone B showed a good lap joint with a smooth surface; and condition zone $\mathrm{C}$ showed no lap-joint formation. The borderline of each area corresponds to the heat-input parameter of FSW, $Q=R / V$ (where $R=$ rotation speed; $V=$ welding speed) [11]. At excess heat input, the shoulder sank into the brass sheet and pushed out the softened metal as a large burr, damaging the probe tip because of severe contact with the steel surface. The temperature history during welding $[9.8 \mathrm{kN}, 1500 \mathrm{rpm}, 750$ $\mathrm{mm} / \mathrm{min}$ ] was measured at both the joint and brass surfaces. The temperature measurement position and history are shown in Fig. 4. The results show that the maximum temperature at the joint interface was $587^{\circ} \mathrm{C}$. The position at which the temperature was measured was not the center of the welding zone; therefore, it is expected that the true maximum temperature during welding was $>587{ }^{\circ} \mathrm{C}$. The effect of $Q$ on the tensile shear strength of the brass and steel FSW lap joint is shown in Fig. 5. As the heat input increased, the tensile shear strength per unit width increased and tended to be close to the saturated value. The joints were fractured at the brass/steel interface except in the case of excess heat input, in which the fracture position changed to the brass side owing to the decreased thickness of stir zone.

The macrostructure of the joint cross section, TEM microstructures of the joint interface, and element distributions of $\mathrm{Fe}, \mathrm{Zn}$, and $\mathrm{Cu}$ are shown in Figs. 6 (a)-(e). The tool force was $14.7 \mathrm{kN}$, tool rotation speed was $1250 \mathrm{rpm}$, welding speed was $1000 \mathrm{~mm} / \mathrm{min}$, and probe length was $3.0 \mathrm{~mm}$. At the interface shown in Fig. 6 (b), small steel particles are distributed in brass, as can clearly be seen in the element distribution in Figs. 6 (c)-(e), which suggests contact of the probe tip to the steel interface.

\subsection{Results using WC-Co tool}

The effect of rotation speed and welding speed on the friction-stir weldability of the lap joint at tool force $9.8 \mathrm{kN}$ using the WC-Co tool with a $2.9-\mathrm{mm}$-long probe is summarized in Fig. 7. Condition zone A resulted in excess burrs; condition

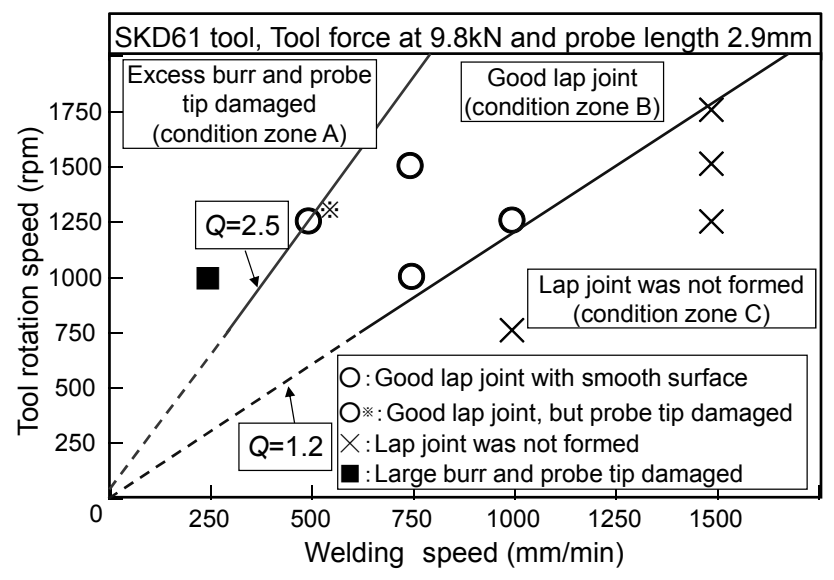

Fig. 3 Combined effect of tool rotation speed and welding speed on weldability in FSW brass-steel lap joint.

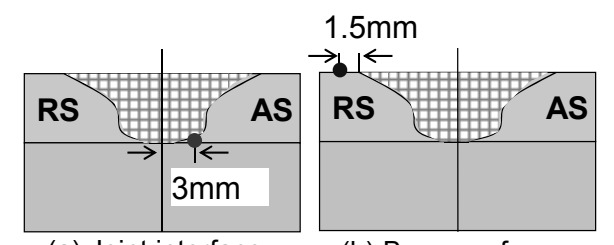

(a) Joint interface

(b) Brass surface Temperature measurement position

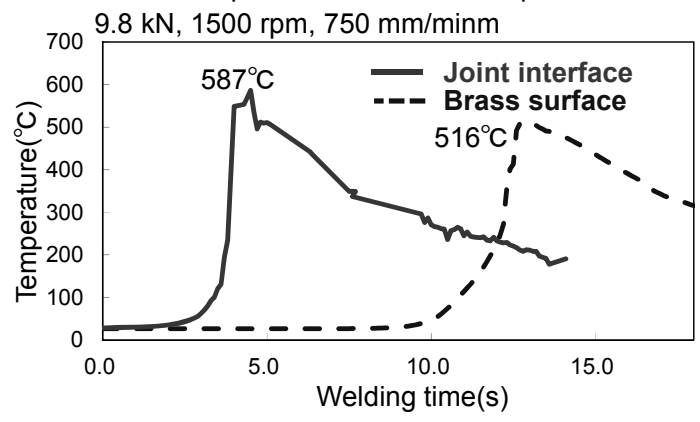

Fig. 4 Temperature measurement position and temperature history during welding at $9.8 \mathrm{kN}, 1500 \mathrm{rpm}, 750 \mathrm{~mm} / \mathrm{min}$. 


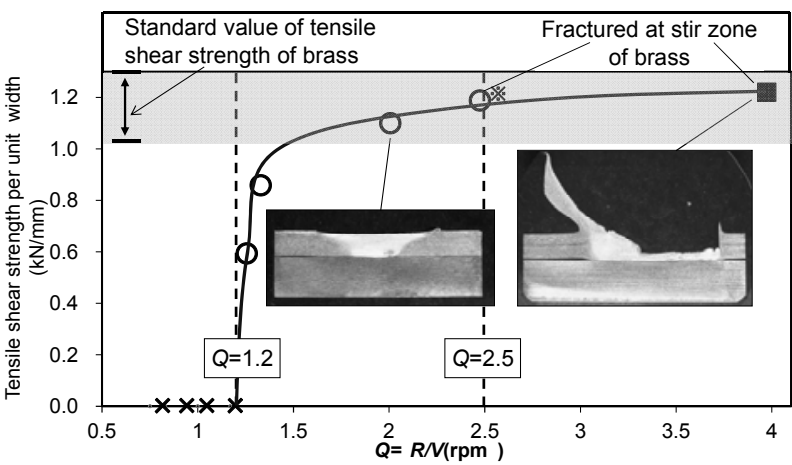

Fig. 5 Effect of $Q$ on tensile shear strength per unit width of brass and steel FSW lap joint at tool force $9.8 \mathrm{kN}$.

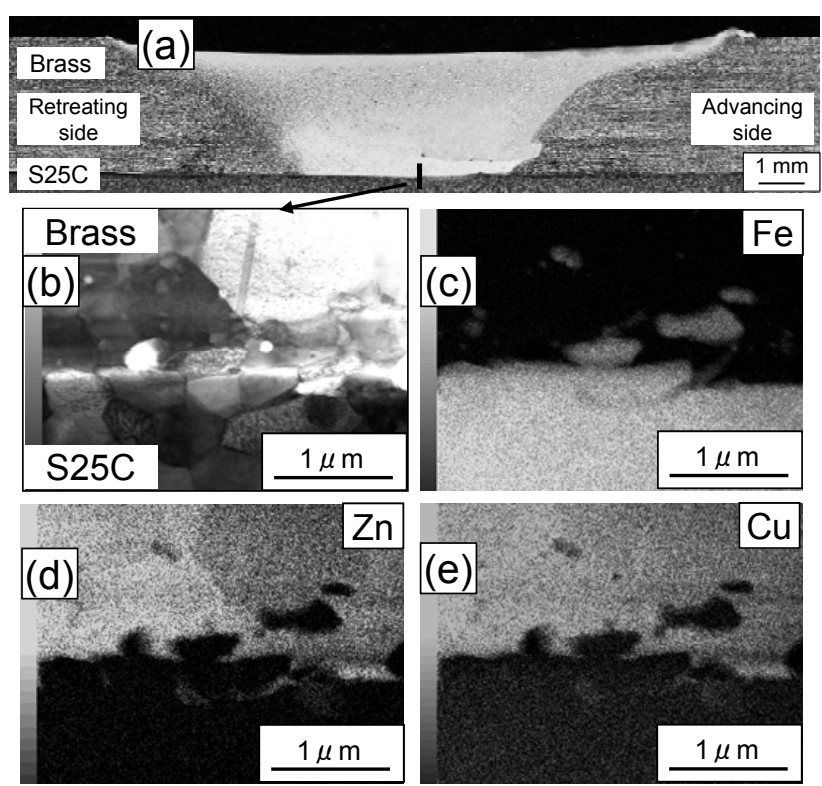

Fig. 6 Cross section of macrostructure (a), TEM microstructure (b) and element area distributions of (c) $\mathrm{Fe}$, (d) $\mathrm{Zn}$, and (e) $\mathrm{Cu}$ at the joint interface: $14.7 \mathrm{kN}, 1250 \mathrm{rpm}, 1000 \mathrm{~mm} / \mathrm{min}$, and probe length $3.0 \mathrm{~mm}$.

zone B showed a good lap joint with a smooth surface; and condition zone $\mathrm{C}$ showed no lap-joint formation, results that are similar to those found with the SKD61 tool. However, whereas the SKD61 probe tip was damaged because of severe contact with the steel surface at high heat input, the $\mathrm{WC}-$ Co probe tip was not damaged and it was possible to use it repeatedly. The upper and lower heat input boundaries of the optimum condition range for a good lap joint were different from those found using the SKD61 tool. The upper boundary increased from $Q=2.2$ to $Q=3.5$, because the $\mathrm{WC}-\mathrm{Co}$ tool made it possible to weld a joint at a higher heat input. The lower boundary increased from $Q=1.2$ to $Q=1.5$, because the WC-Co tool had no thread and thus the plastic flow was lower than that of the SKD61 tool. Moreover, the thermal conductivity of the WC-Co tool was higher than that of the SKD61 tool. The effect of $Q$ on the tensile shear strength of the brass and steel lap joint is shown in Fig. 8. As the heat input increased, the tensile shear strength per unit width increased, approaching the saturated value. The joints were fractured at the brass/steel interface except in the case of excess heat input, in which the fracture position changed to the brass side owing to the decreased thickness of the stir zone, as was found with the SKD61 tool.

The microstructure of the joint in cross section, TEM microstructures of the joint interface, and element distribution of $\mathrm{Fe}, \mathrm{Zn}$, and $\mathrm{Cu}$ are shown in Figs. 9 (a)-(e) at tool force $9.8 \mathrm{kN}$, tool rotation speed $1250 \mathrm{rpm}$, welding speed $500 \mathrm{~mm} / \mathrm{min}$, and probe length $2.9 \mathrm{~mm}$ using the WC-Co tool. Fig. 9 (b) shows a lumpy interface because of the contact of the probe tip to the steel interface. The result of line analysis at the interface is shown in Fig. 10, which shows a diffusion zone within a range of $\sim 50 \mathrm{~nm}$.

Yasui et al. [12] reported that a A6063 Al alloy/S45C steel butt joint was successfully made by using FSW, in which the probe lightly touched the steel. The joining mechanism of this method is as follows: first, the probe scuffs the surface of the S45C steel and forms a bare surface; then, the $\mathrm{Al}$ alloy adheres by plastic flow to the bare surface, forming a reaction layer. Under high heat-input conditions, a 400 -nm-wide compound layer $\left(\mathrm{Fe}_{2} \mathrm{Al}_{5}\right.$ and $\mathrm{FeAl}$ ) is formed while at low heat-input conditions, an 800 -nm-wide laminated structure is built up from the layers of $\mathrm{Al}$ and $\mathrm{Fe}$.

In this study, the existence or nonexistence of a compound layer was checked by using the electron diffraction analysis in TEM at the joint interface as shown in Fig. 11. The results show that there is no compound layer or laminated structure at the joint interface. Based on these results, it is considered that the main mechanism of this lap joint is mutual diffusion of the elements at the bare surface caused by the contact of the tool tip to the steel surface.

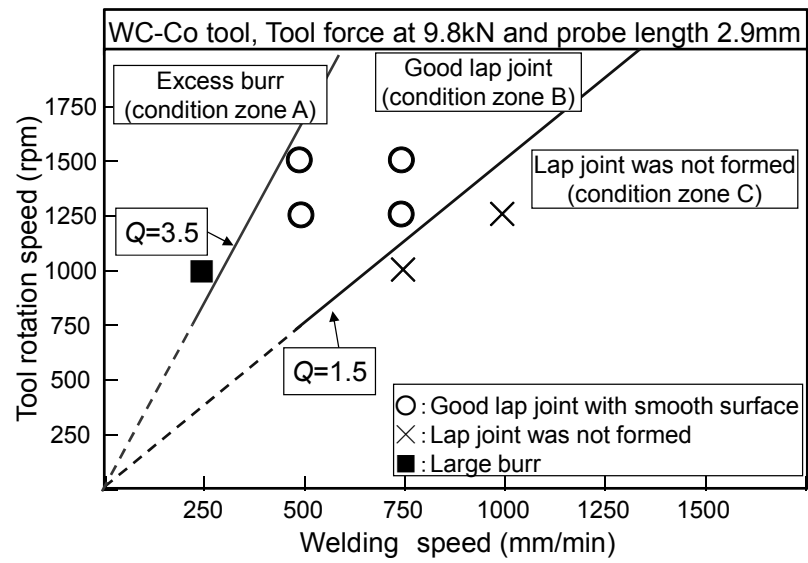

Fig. 7 Combined effect of tool rotation speed and welding speed on weldability of FSW brass-steel lap joint using WC-Co tool. 


\section{Conclusions}

A lap joint of a brass sheet on steel plate with a smooth surface and good joint strength was successfully made by employing FSW. The main mechanism of this lap joint is the mutual diffusion of elements at the bare surface caused by the contact of the tool tip with the steel surface. This result shows that friction-stir lap-joining by FSW has significant potential as a cladding process for brass sheet on steel plate for tribological applications.

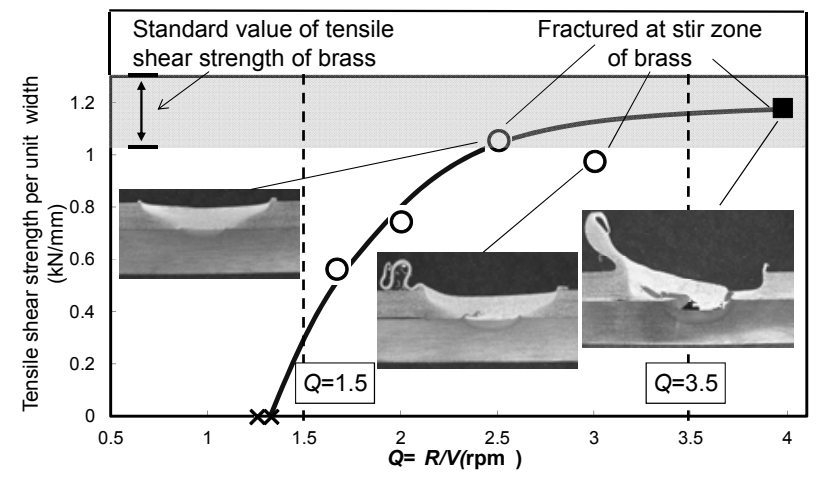

Fig. 8 Effect of $Q$ on tensile shear strength per unit width of brass and steel FSW lap joint at tool force $9.8 \mathrm{kN}$.
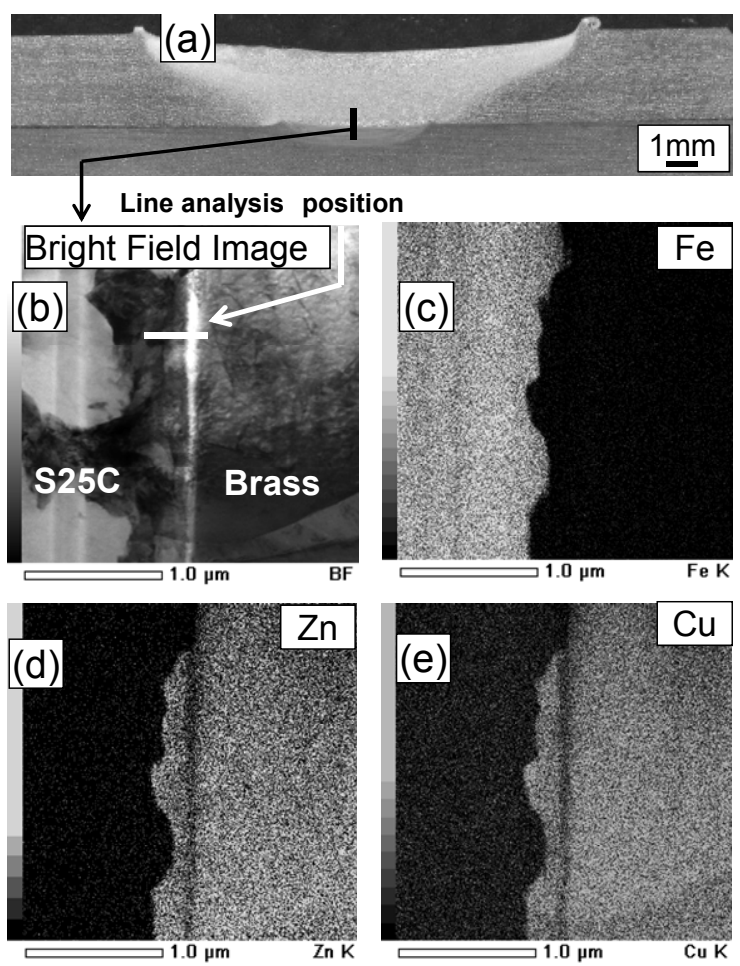

Fig. 9 Cross section of macrostructure (a), TEM microstructure (b) and element area distributions of (c) $\mathrm{Fe}$, (d) $\mathrm{Zn}$, and (e) $\mathrm{Cu}$ at the joint interface: $9.8 \mathrm{kN}, 1250 \mathrm{rpm}, 500 \mathrm{~mm} / \mathrm{min}$, and probe length $2.9 \mathrm{~mm}$.

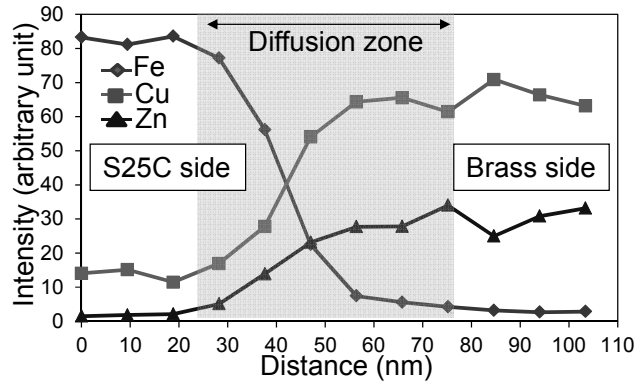

Fig. 10 Element distributions of $\mathrm{Fe}, \mathrm{Cu}$, and $\mathrm{Zn}$ at the joint interface evaluated by line analysis of TEM image in Fig. 9 (b).
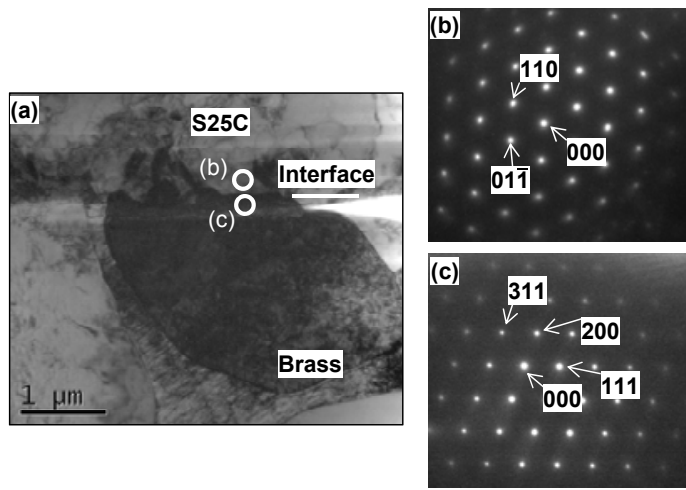

Fig. 11 TEM micrograph of joint interface, :(a) bright field image and selected area electron diffraction patterns of (b) $\alpha$-Fe and (c) $\mathrm{CuZn} ; 9.8$ $\mathrm{kN}, 1250 \mathrm{rpm}, 500 \mathrm{~mm} / \mathrm{min}$, and probe length $2.9 \mathrm{~mm}$.

\section{References}

[1] K. Kimapong and T. Watanabe, Mater. Trans., 46 (2005) 835-841.

[2] Y.C. Chen, T. Komazaki, Y.G. Kim, T. Tsumura and K. Nakata, Mater. Chem. Phys., 111 (2008) 375-380.

[3] Y.C. Chen and K. Nakata, Mater. Trans., 50 (2009) 2598-2603.

[4] J.S. Liao, N. Yamamoto, H. Liu and K. Nakata, Mater. Lett., 64 (2010), 2317-2320.

[5] K.H. Song, W.Y. Kim and K. Nakata, Mater. Des., 35 (2012), 126-132.

[6] Y.C. Chen and K. Nakata, Scr. Mater., 58 (2008), 433-436.

[7] A.A. Zadeh, T. Saeid and B. Sazgari, Alloy. Compd., 460 (2008) 535-538.

[8] T. Saeid, A.A. Zadeh and B. Sazgari, Alloy. Compd., 490 (2010) 652-655.

[9] P. Xue, B.L. Xiao, D. Wang and Z.Y. Ma, Sci. Technol. Weld. Joining, 16 (2011) 657-661.

[10] V. Firouzdor and S. Kou, Mettall. Mater. Trans. A, 43 (2012) 303-315.

[11] Y.G. Kim, H. Fujii, T. Tsumura, T. Komazaki and K. Nkakata, 
Mater. Sci. Eng., A, 415 (2006) 250-254.

[12] T. Yasui, Y. Shimoda, T. Ishii, M. Tsubaki and M. Fukumoto, Q. J. Jpn. Weld. Soc., 25 (3) (2007) 426-430. 